\title{
Comparative study of adhesive systems applied to different regions of dental substrate
}

Veridiana Camilotti ${ }^{a}$, Virgínia Bosquiroli ${ }^{a}$, Máx Dobrovolski ${ }^{b}$, Mario Alexandre Coelho Sinhoreti ${ }^{\mathrm{C}}$, Priscilla do Monte Ribeiro Busato ${ }^{a}$,Lyvia Karla Cerci Ferreira Bertacchini ${ }^{\mathrm{b}}$, Márcio José Mendonça ${ }^{\mathrm{a}}$

\begin{abstract}
OBJECTIVE: The aim of this study was to evaluate the bond strength (BS) of different self-etching adhesive systems to bovine dentin.

METHODS: For this purpose, 50 teeth were flattened with silicon carbide abrasive papers and randomly divided into 5 groups: SB - Single Bond Plus; Group AEO - Adper Easy One; Group ADH - AdheSE; Group ASE - Adper SE Plus and Group Clear - Clear Fill. After adhesive system application, 5 Tygon cylinders $(1.8 \mathrm{~mm} \times 2 \mathrm{~mm})$ were placed on the vestibular surface of each tooth, filled with resin composite (Filtek Z350) and light activated. Three composite resin cylinders were fabricated for each bovine crown, one being located in the incisal region, one in the middle third and one in the cervical region, totaling 30 composite resin test specimens (TS) for each group. The TS were submitted to the microshear bond strength test in a Universal Test Machine (Kratos), at a cross-head speed of $0.5 \mathrm{~mm} / \mathrm{min}$.

RESULTS: The BS was calculated and analyzed by ANOVA (one-way) and Tukey's test $(p<0.05)$. The highest BS values were obtained in Group SB and there were no significant differences between the adhesive systems tested in the middle and cervical thirds. In the fracture type analysis it was found that adhesive failure was dominant for all groups.

CONCLUSION: The conventional two-step adhesive system SB presented the highest bond strength mean to bovine dentin for all the regions.
\end{abstract}

Key words: Self-etching adhesive; Bond strength; Bovine dentin

\section{Estudo comparativo acerca da aplicação de sistema adesivo em diferentes regiões do substrato dental}

\section{RESUMO}

OBJETIVO: O objetivo do presente estudo foi avaliar a força de adesão (FA) de diferentes sistemas adesivos auto-condicionantes aplicados na dentina bovina.

METODOS: 50 dentes bovinos foram desgastados com lixas abrasivas e divididos aleatoriamente em 5 grupos: SB - Single Bond Plus; AEO - Adapter Easy One; ADH - AdheseSE; ASE - Adapter SE Plus and CLEAR - Clear Fill. Após a aplicação do sistema adesivo, 5 cilindros de Tygon $(1,8 \mathrm{~mm} \times 2 \mathrm{~mm})$ foram posicionados na superfície vestibular de cada dente, preenchidos com resina composta (Filtek Z350) e fotopolimerizados. Três cilindros de resina composta foram produzidos para cada coroa de dente bovino, um localizado na porção incisal, um no terço médio e outro na porção cervical, totalizando 30 corpos de prova (CP) para cada grupo. Os CP foram submetidos à Máquina de Teste Universal (Kratos) para avaliar a força de resistência à microtração, sob força constante de 0,5 mm/min. A FA foi calculada e analisada através do ANOVA de uma via e post hoc de Tuckey $(p<0,05)$.

RESULTADOS: A maior FA foi obtida no grupo SB e não houve diferença significante entre os sistemas testados nos terços médio e cervical. Após a análise do tipo de fratura, foi constatada a maior prevalência de falha adesiva em todos os grupos.

CONCLUSÃO: O adesivo de dois passos SB apresentou a maior força de adesão nas no terço incisal de dentes bovinos quando comparado a adesivos autocondicionantes.

Palavras-chave: Adesivo autocondicionante; Força de adesão; Dentes bovinos.

\author{
${ }^{a}$ Assistant Professor, Department of Restorative \\ Dentistry, State University of West Parana \\ b Student, State University of West Parana \\ c Professor, Dental Materials, Piracicaba Dental \\ School (UNICAMP)
}

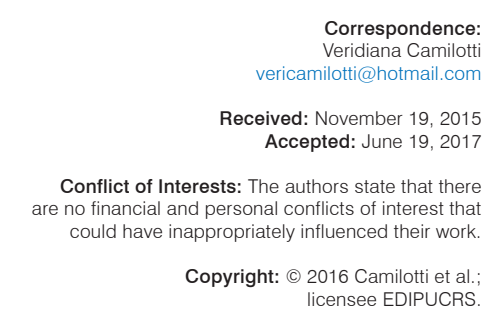

This work is licensed under a Creative Commons Attribution 4.0 International License. 


\section{INTRODUCTION}

To improve the clinical and biologic longevity of resin composite restorations, the interaction of the adhesive system with the dental structure is of great importance. Several studies have demonstrated the progress in development of dentinal adhesives to increase the clinical performance of esthetic restorations [1].

Adhesive systems are generally divided into conventional and self-etching types [2]. The conventional types are characterized by the presence of a demineralizing agent, $37 \%$ phosphoric acid, and a combination of primer and resin adhesive that may be in the same bottle, denominated a conventional 2-step adhesive system, or in separate bottles, considered a conventional 3-step adhesive system. Phosphoric acid is capable of completely removing the smear layer after etching and can also cause collapse of the collagen fibers at the time of drying the demineralized dentin. This results in incomplete infiltration into the demineralized areas, and formation of zones of pores under the hybrid layer [3]. Post-operative sensitivity has also been associated with the action of phosphoric acid in conventional adhesive systems, which motivate the development of a self-etching primer [4].

Self-etching adhesive systems are characterized by the absence of $37 \%$ phosphoric acid. These systems contain an acidic primer that combines a demineralizing agent with the primer. The resin adhesive may be presented in the same bottle, being denominated a onestep self-etching adhesive system, or be in a separate bottle, characterized as a two-step self-etching adhesive system [5].

Self-etching adhesive systems have high concentrations of acidic monomers in the primers in their composition, therefore they are able to dissolve and/or change the smear layer and the superficial portion of the subjacent dentin. Better sealing of the dental structure may occur with these adhesive systems, since there will be no discrepancy between the etching depth and extension of resin monomer infiltration into the substrate. Thus, it would result in less, or none, postoperative sensitivity [6].

Whatever the classification of adhesive systems may be, they all contain similar ingredients, irrespective of the number of bottles in which an adhesive is presented [7]. Traditionally, adhesives contain acrylic resin monomers, organic solvents, initiators and inhibitors, and sometimes, load particles. It is evident that all the components have their specific function. Various studies have been conducted to evaluate the bonding effectiveness of adhesive systems. Recently adhesive formulations have been proposed with the aim of improving the quality of the bond interface, thus, a comparative study of these adhesive systems is necessary [5].

Therefore, the purpose of this study was to evaluate the effectiveness of the bond to dentin of the conventional and self-etching adhesive systems using the microshear test.

\section{METHODS}

To conduct this study, 50 bovine incisors extracted at least one month before the experiment began were used. The tooth crowns were immersed in physiological solution and stored under refrigeration at a temperature of $4^{\circ} \mathrm{C}$. Before preparing the test specimens, the bovine tooth crowns were cut in order to obtain a rectangular shape of approximately $15 \mathrm{~mm}$ length and $10 \mathrm{~mm}$ width. After this, the teeth were embedded in acrylic resin (JET, Rio de Janeiro-RJ, Brazil) in plastic PVC cylinders (TIGRE ${ }^{\circledR}$, Joinville - SC, Brazil), measuring $20 \mathrm{~mm}$ in external diameter by $14 \mathrm{~mm}$ high, with the vestibular face facing up and projected $1 \mathrm{~mm}$ beyond the embedding cylinder edge.

With the aid of a horizontal polishing machine (APL-4, Arotec S.A. São Paulo-SP, Brazil.) and silicon carbide water abrasive papers with 400, 600, 800, 1000 and 1200 grit (Carborundum, S. S. White Company, Philadelphia, USA.), the surfaces were wet-abraded by approximately $1 \mathrm{~mm}$, under water cooling, with the purpose of obtaining a flat surface in dentin. After this procedure, the sample surfaces were examined under a stereoscopic loupe (Carl Zeiss, Germany), at 50X magnification, to ensure that there were no areas of exposed enamel in the test region.

The test specimens were randomly divided into five groups according to the adhesive system to be used: Group SB - Single Bond Plus (3M ESPE, Dental Products, St. Paul, MN, USA) adhesive system; Group AEO - Adapter Easy One (3M ESPE, Dental Products, St. Paul, MN, USA) adhesive system; Group ADH -AdheSE (Ivoclar/Vivadent, Schaan, Liechtenstein) adhesive system; Group ASE - Adper SE Plus (3M ESPE, Dental Products, St. Paul, MN, USA) and Group Clear - Clear Fill (Kuraray Co., Ltda., Tokyo, Japan) adhesive systems. The adhesive systems were used in accordance with the manufacturers' specifications (Table 1).

The resin composite cylinders were fabricated with the use of a Tygon matrix (Tygon tubing, TYG -030, SaintGobain Performance Plastic, Maime Lakes, FL, USA) with an internal diameter of $1.8 \mathrm{~mm}$ and height of $2 \mathrm{~mm}$. The matrix was positioned over the treated dentin, and the resin composite Filtek ${ }^{\mathrm{TM}}$ Z100 (3M ESPE, Dental Products, St. Paul, MN, USA) was inserted with a spatula (Thompson \#6, Miltex, inc., Tuttlingen, Germany). Light activation was performed with a QTH curing light Optilux 401 (Demetron/ Kerr, Danbury, CT, EUA) appliance for 40 seconds. Three resin composite cylinders were fabricated for each bovine crown, one being located in the incisal region, one in the middle third and one in the cervical region, totaling 30 resin composite test specimens for each group. After this, the matrix was section and removed with a \#12 scalpel blade, and the specimens were stored in physiological solution at $37^{\circ} \mathrm{C}$ for 24 hours, being submitted to the microshear bond strength test after this period.

The test specimens were coupled to the universal test machine (Instron 1000, Testing Machine-Model 5565, Canton MA, EUA) for measuring the microshear bond strength. By means of a chisel-shaped steel blade on the resin 
Table 1. Description of Materials Used

\begin{tabular}{|c|c|c|c|}
\hline Material & $\mathrm{pH}^{*}$ & Composition & Bonding Procedure \\
\hline Single Bond 2 (3M/ ESPE) & 4.25 & $\begin{array}{l}\text { BisGMA, HEMA, dimethacrylates, ethanol, } \\
\text { water, an innovative photoinitiator system } \\
\text { and a functional copolymer of polyacrylic and } \\
\text { polyalkenoic acid methacrylate. }\end{array}$ & $\begin{array}{l}\text { Etching with phosphoric acid for } 15 \text { seconds. } \\
\text { Wash for } 10 \text { seconds. } \\
\text { Dry with absorbent paper. } \\
\text { Adhesive application for } 10 \text { seconds. } \\
\text { Apply jets of air for } 5 \text { seconds. } \\
\text { Light activate for } 10 \text { seconds. }\end{array}$ \\
\hline Adper Easy One (3M/ ESPE) & 2.8 & $\begin{array}{l}\text { Phosphated methacrylate Esters, Vitrebond }{ }^{\mathrm{TM}} \\
\text { copolymers, nanoparticles for loading, ethanol, } \\
\text { dimethacrylates, HEMA, water and initiators. }\end{array}$ & $\begin{array}{l}\text { Agitate the product. } \\
\text { Leave the dentin clean and slightly humid. } \\
\text { Apply the adhesive with friction for } 20 \text { seconds. } \\
\text { Apply gentle jets of air for } 5 \text { seconds. } \\
\text { Light activate for } 10 \text { seconds. }\end{array}$ \\
\hline AdheSe (Ivoclar/Vivadent) & 1.4 & $\begin{array}{l}\text { Primer: Dimethacrylate, phosphoric acid, acrylic, } \\
\text { water, initiators and stabilizers. } \\
\text { Adhesive: Dimethacrylate, hydroxyethyl } \\
\text { methacrylate (HEMA), SiO2, initiators and } \\
\text { stabilizers. }\end{array}$ & $\begin{array}{l}\text { Apply the primer with friction on the clean tooth } \\
\text { for } 30 \text { seconds. } \\
\text { Apply strong jet of air for } 5 \text { seconds. } \\
\text { Adhesive application for } 30 \text { seconds. } \\
\text { Light activate for } 10 \text { seconds. }\end{array}$ \\
\hline Adper SE Plus/ 3M/ESPE & 0.8 & $\begin{array}{l}\text { Bottle A: water, HEMA, surfactants and pink } \\
\text { coloring agent. } \\
\text { Bottle B: UDMA, TEGDMA,TMPTMA, } \\
\text { HEMA, MHP, nanoparticles of zirconium, } \\
\text { camphorquinone. }\end{array}$ & $\begin{array}{l}\text { Apply the primer actively on the clean dentin } \\
\text { until it turns a completely pink color, do not apply } \\
\text { the jet of air. } \\
\text { Apply the adhesive on the pink dentin for } \\
20 \text { seconds. } \\
\text { Apply jet of air for } 10 \text { seconds. } \\
\text { Light activate for } 10 \text { seconds. }\end{array}$ \\
\hline Clearfil SE Bond/ Kuraray & 2.0 & $\begin{array}{l}\text { Primer: 10-MDP, HEMA, hydrophilic } \\
\text { dimethacrylate, photoinitiator and water. } \\
\text { Adhesive: 10-MDP, BisGMA, HEMA, } \\
\text { dimethacrylate and microparticles for loading. }\end{array}$ & $\begin{array}{l}\text { Apply the primer with friction on the clean tooth } \\
\text { for } 30 \text { seconds. } \\
\text { Apply jet of air for } 5 \text { seconds. } \\
\text { Adhesive application for } 30 \text { seconds. } \\
\text { Light activate for } 10 \text { seconds. }\end{array}$ \\
\hline
\end{tabular}

* Values informed by the manufacturers.

composite/bovine dentin interface, a compression load was applied at a cross-head speed of $0.5 \mathrm{~mm} / \mathrm{min}$, until fracture.

The failure modes were evaluated under a stereoscopic loupe at 40X magnification (Lambda LEB-3 no 18233, Sao Paulo, SP-Brazil) and classified as: Cohesive in Dentin (CD), failure exclusively in the dentin; Cohesive in Resin (CR), failure exclusively in the resin composite; Adhesive (A), failure at the resin/dentin interface, or Mixed Adhesive (MA), failures at the resin/dentin/cement interface, which included cohesive failures in the neighboring substrates.

The bond strength values of each test specimen and region were submitted to the ANOVA (two-way) and comparative analysis was performed by the Tukey's test.

\section{Evaluation by Scanning Electron Microscopy (SEM)}

For analysis of the dentin etching pattern, surface hybridization was performed corresponding to each sample group according to the manufacturers' standards. Before light polymerization, the test specimens were rinsed in alternate baths of ethanol and acetone ( 20 seconds each) to remove the unpolymerized monomers [8]. The hemi-teeth were stored in a desiccator containing silica gel for 12 hours. After this, they were mounted on supports and gold sputtered (Balzers SCD 050 Sputter Coater, Bal-Tec, Germany) for observation by scanning electron microscopy (Philips XL30; Eindhoven, Holland) at $15 \mathrm{kV}$ accelerating voltage.

\section{RESULTS}

The bond strength means by the microshear bond strength test are represented in Figure 1. The data about the influence of the region are represented in Table 2. The failure modes are shown in Table 3.

The result of the ANOVA showed that the conventional adhesive system ASB presented the highest bond strength values with statistical significance, in comparison with the other adhesive systems. The adhesive system AEO presented the lowest bond strength values with significance. The twostep self-etching adhesive systems Clear and ASE were statistically similar between them. The adhesive system AdheSE presented statistically similar bond strength values to those of the AEO, Clear and ASE systems.

Table 2 shows that for the incisal region, the conventional adhesive system ASB presented the highest bond strength values, followed by the self-etching adhesive system Clear. The self-etching system AEO, ADE, ASE and Clear presented no statistically differences among them for the incisal region. In the middle third region, all the adhesive systems presented statistically similar results among them, with the exception of the self-etching system AEO, which presented the lowest bond strength values. For the cervical third region, the results for adhesive systems ASB and Clear were statistically similar between them and showed higher values than those of the other adhesive systems. The adhesive 
systems AEO, ADE and ASE presented no statistically significant differences among them for the cervical region. When the influence of the three regions evaluated for each system were compared, it was possible to find that the middle third and cervical regions for all adhesive systems presented statistically similar bond strength values. For the incisal third region the conventional adhesive system presented the highest bond strength values.

The failure mode was predominantly adhesive for all the evaluated adhesive systems (Table 3).
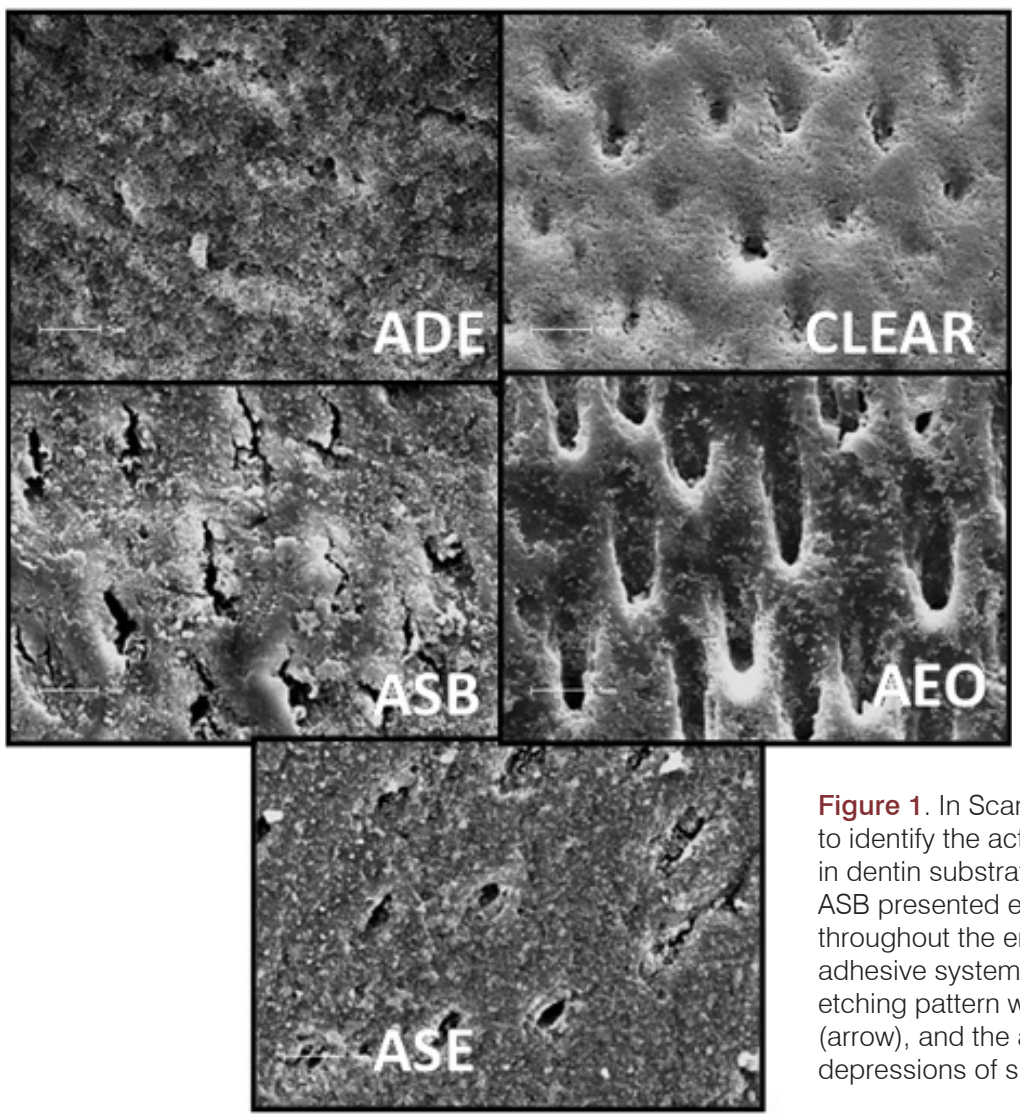

Figure 1. In Scanning Electron Microscopy, it is possible to identify the action of the adhesive systems evaluated in dentin substrate. The conventional adhesive system ASB presented extensive and broad depressions throughout the entire surface (arrows). The self-etching adhesive systems ADE and Clear presented a surface etching pattern with narrow and shallow depressions (arrow), and the adhesive system AEO presented wide depressions of shallow depth.

Table 2. Microshear bond strength means (MPa)

\begin{tabular}{lcccc}
\hline \multicolumn{1}{c}{$\begin{array}{c}\text { Adhesive } \\
\text { Systems }\end{array}$} & \multicolumn{4}{c}{ Regions Evaluated } \\
\cline { 2 - 5 } \multicolumn{1}{c}{ Incisal } & \multicolumn{1}{c}{ Middle } & Cervical \\
ASB & $35.08(4.94)^{\mathrm{Aa}}$ & $28.94(8.69)^{\mathrm{Aa}}$ & $22.45(3.64)^{\mathrm{Ba}}$ \\
AEO & $13.03(3.64)^{\mathrm{Ac}}$ & $12.67(3.72)^{\mathrm{Ab}}$ & $16.29(2.82)^{\mathrm{Ab}}$ \\
$\mathrm{ADE}$ & $16.32(4.84)^{\mathrm{Ac}}$ & $15.85(4.11)^{\mathrm{Aab}}$ & $19.88(6.03)^{\mathrm{Abc}}$ \\
ASE & $16.89(3.45)^{\mathrm{Ac}}$ & $18.35(3.53)^{\mathrm{Aab}}$ & $19.22(2.80)^{\mathrm{Abc}}$ \\
CLEAR & $22.26(2.70)^{\mathrm{Ab}}$ & $21.42(8.54)^{\mathrm{Aab}}$ & 17.44 & $(4.03)^{\mathrm{Aac}}$ \\
\hline
\end{tabular}

( ) - standard deviation. Different letters mean statistically different values. Lower case letters indicate the evaluation among adhesive systems (in column). Capital letters indicate evaluation among regions (in row).

Table 3. Failure modes

\begin{tabular}{lccc}
\hline \multicolumn{1}{c}{$\begin{array}{c}\text { Adhesive } \\
\text { Systems }\end{array}$} & $\begin{array}{c}\text { Adhesive } \\
(\%)\end{array}$ & $\begin{array}{c}\text { Mixed } \\
(\%)\end{array}$ & $\begin{array}{c}\text { Cohesive } \\
(\%)\end{array}$ \\
\hline ASB & 98 & 1 & 1 \\
AEO & 97 & 2 & 1 \\
ADE & 98 & 1 & 1 \\
ASE & 98 & 1 & 1 \\
CLEAR & 97 & 2 & 1 \\
\hline
\end{tabular}

\section{DISCUSSION}

For bond strength tests in laboratory researches, human or bovine teeth can be used. In the present study, bovine teeth were preferred because of being easily obtainable, in addition to presenting similar histology to that of the human tooth [9], as well as demonstrating similar bond strength values, thus allowing their use in microshear tests $[10,11]$. In this type of test, preparation of the dental samples is facilitated by the action of silicon carbide abrasive papers. The use of the matrix on the hybridized dentin enabled standardized test specimens to be fabricated, with small bond areas, which is considered an advantageous aspect, according to the reports of several authors $[6,12]$.

The use of conventional adhesive systems that require the prior application of phosphoric acid implies a high degree of sensitivity in performing the humid technique, which may compromise the efficacy of the bond and marginal sealing of these adhesives. Excessive drying and incomplete solvent removal are common errors associated with this technique according to Erickson et al. [13], this is why these adhesive present better bond strength values to enamel. Nevertheless, 
the results found in the present study showed that the conventional adhesive system presented statistically higher values than the two-step self-etching systems to bovine dentin, a result similar to that found by Erickson et al. [13], whereas the self-etching systems presented a better bond to dentin than to enamel [2].

The adhesive system Clearfil ASES presented significantly higher bond strength values than the other self-etching adhesive systems tested, which corroborates previous in vitro and in vivo studies of Sharafeddin et al. $[14,15]$. These results correspond to innumerable factors, with the simultaneous demineralization and infiltration of the adhesive system into the dentinal substrate being the most important. These two simultaneous actions are responsible for the formation of a thin, but uniform layer of resin-infiltrate in the dentin, with support from the hydroxyapatite available for the chemical reactions studied by Van Meerbeek et al. $[2,16]$.

According to recent researches $[2,17,18]$, adhesive systems with different $\mathrm{pHs}$ may produce different etching patterns in enamel and dentin due to their difference in acidity and aggressiveness. Based on these characteristics, the self-etching adhesives may be classified as "strong" and "weak" by Hashimoto et al. $[19,20]$. Those that present $\mathrm{pH} \leq 1$ are considered "strong", producing enamel and dentin demineralization similar to etching with phosphoric acid. In Figure 1, it is possible to observe the similarity in the dentin demineralization pattern of the conventional adhesive system ASB and of the "strong" self-etching type ASE. Those that present a $\mathrm{pH}$ with a value of approximately 2 are considered "weak" and do not have the same demineralizing capacity as phosphoric acid, reaching a depth of only 1 $\mathrm{mm}$ in dentin like explained by Zhou et al. [7]. This, does not agree with the findings of the present study, in which the less acid adhesive system (Clear pH 2.0) was the one that reached the highest bond strength values. The acid etching pattern of dentin by systems classified as "weak" is more superficial, promoting irregular and less retentive surfaces.

The one-step adhesive system presented statistically lower bond strength values when compared with the other systems evaluated. The possible explanation for these results is the proportion of their constituents. Both have functional and reactional monomers, solvents, inhibitors and activators, but in different proportions by Carvalho et al. [21]. The one-step adhesive systems normally have a smaller quantity of reactional monomers. As these monomers provide less mechanical resistance, there is less potential bond strength for the one-step adhesive systems. However, these monomers are specific and may not apply to the recently introduced systems [18].

Garcia et al. [6] evaluated the bond strength of onestep and two-step self-etching adhesive systems by the microshear bond strength test. The two-step products resulted in higher mean bond strength values, in comparison with the clinical one-step type, with statistically significant difference between them. The one-step self-etching adhesive systems are more hydrophilic and form a hybrid layer that is more permeable to water. This layer exhibits microscopic channels filled with water and allow its movement in the layer formed between the adhesive and composite. Clinically, it is not easy to remove the water from these adhesive solutions [22].

The results of the present study revealed that even with the high degree of sensitivity of the conventional technique, it showed statistically higher bond strength in comparison with the self-etching adhesives. For Van Meerbeek et al. [2], the conventional 3-step adhesive systems showed better results than the two-step type. Authors also observed that the two-step self-etching adhesive systems presented better results than the one-step type. The highest bond strength values found, coincided precisely with those products that contain hydrophilic (primer) and hydrophobic (adhesive) components in separate bottles.

When the influence of the dentin region on bond strength values was evaluated, it was observed that the one-step selfetching adhesive system AEO and the two-step systems $\mathrm{ADE}$ and ASE presented a significantly lower performance for the cervical region. Dentin wetness increases towards the pulp because of increasing tubular density and luminal diameter [23]. This fact is in agreement with the results found by Adebayo et al. [24] and may be justified by the increase in density and diameter of the dentinal tubules in this region. Therefore, the hydrolytic solubility of the functional and cross-linking adhesive monomers may become more important in dentin bonding at this depth due to the greater water content. Following on from this, bonding in deep dentin may be affected by the reduced fibril network area and hence contribute to the reduced bond strengths in deep dentin with the tubule orientation perpendicular to the surface according to Camilotti et al. [25] and Singh et al. [26].

The bond strengths of the tested self-etching adhesive systems were not significantly altered considering the location of the test specimens. This fact is corroborated by the findings of Sattabanasuk et al. [27], who found no differences in the shear bond strength of the 2-step adhesive system to deep dentin with tubule orientation perpendicular to the surface. These adhesive systems appear to bond equally well to dentin with tubule orientation perpendicular or parallel/oblique to the surface. This may guarantee a more uniform stress distribution in restorations with these adhesives placed in deep cavities (Figure 1).

In all the groups adhesive failure predominated, in agreement with other studies like Ikeda et al. [28]. The exclusively adhesive failures allowed real bond strength between the material and dental structure, since the conventional tests with bond strength values higher than $20 \mathrm{MPa}$ indicated cohesive failure in dentin, as they were unable to measure high values [19]. Clinical tests would be of great relevance to confirm the data obtained in this laboratory study, to establish the real influence of the types of adhesive systems and their relationship with the location of the dentinal substrate. 


\section{CONCLUSIONS}

Based on the results obtained, it could be concluded that:

- The conventional two-step adhesive system ASB presented the highest bond strength mean to bovine dentin for all the regions.

- As regards the three regions evaluated for each adhesive system, it was possible to find that the middle third and cervical regions for all adhesive systems presented statistically similar bond strength values. For the incisal third region the conventional adhesive system presented the highest bond strength values.

\section{REFERENCES}

1. Van Dijken JW, Pallesen U. Randomized 3-year clinical evaluation of Class I and II posterior resin restorations placed with a bulk-fill resin composite and a one-step self-etching adhesive. J Adhes Dent. 2015;17:81-8. https:// doi.org/10.3290/j.jad.a33502

2. Van Meerbeek B, De Munck J, Yoshida Y, Inoue S, Vargas M, Vijay P, Van Landuyt K, Lambrechts P, Vanherle G. Buonocore memorial lecture. Adhesion to enamel and dentin: current status and future challenges. Oper Dent. 2003;28:215-35.

3. Hsu KW, Marshall SJ, Pinzon LM, Watanabe L, Saiz E, Marshall GW SEM evaluation of resin-carious dentin interfaces formed by two dentin adhesive systems. Dent Mater. 2008;24:880-7. https://doi.org/10.1016/j. dental.2007.11.001

4. Perdigão J. New developments in dental adhesion. Dent Clin North Am. 2007;51:333-57. https://doi.org/10.1016/j.cden.2007.01.001

5. Van Landuyt KL, Snauwaert J, De Munck J, Peumans M, Yoshida Y, Poitevin A, Coutinho E, Suzuki K, Lambrechts P, Van Meerbeek B. Systematic Review of the chemical composition of contemporary dental adhesives. Biomaterials 2007;28:3757-85. https://doi.org/10.1016/j. biomaterials.2007.04.044

6. Garcia RN, de Goes MF, Giannini M. Effect of water storage on bond strength of self-etching adhesives to dentin. J Contemp Dent Pract. 2007;8:46-53

7. Zhou L, Wang Y, Yang H, Guo J, Tay FR, Huang C. Effect of chemical interaction on the bonding strengths of self-etching adhesives to deproteinised dentine. J Dent. 2015;43:973-80. https://doi.org/10.1016/j. jdent.2015.05.010

8. Moura SK, Reis A, Pelizzaro A, Dal-Bianco K, Loguercio AD, Arana-Chavez VE et al. Bond strength and morphology of enamel using self-etching adhesive systems with different acidities. J. Appl. Oral Sci. 2009;17:315325. https://doi.org/10.1590/S1678-77572009000400009

9. Rüttermann S, Braun A, Janda R. Shear bond strength and fracture analysis of human vs. bovine teeth. PLoS One. 2013;8:e59181. https:// doi.org/10.1371/journal.pone.0059181

10. Camargo MA, Marques MM, de Cara AA. Morphological analysis of human and bovine dentine by scanning electron microscope investigation. Arch Oral Biol. 2008;53:105-8. https://doi.org/10.1016/j. archoralbio.2007.09.005

11. Reis AF, Giannini M, Kavaguchi A, Soares CJ, Line SR. Comparison of microtensile bond strength to enamel and dentin of human, bovine, and porcine teeth. J Adhes Dent. 2004;6:117-21.
12. Krifka S, Börzsönyi A, Koch A, Hiller KA, Schmalz G, Friedl KH. Bond strength of adhesive systems to dentin and enamel-Human vs. bovine primary teeth in vitro. Dent Mater. 2007;24:888-94. https://doi. org/10.1016/j.dental.2007.11.003

13. Erickson RL, Barkmeier WW, Latta MA. The role of etching in bonding to enamel: a comparison of self-etching and etch-and-rinse adhesive systems. Dent Mater. 2009;25:1459-67. https://doi.org/10.1016/j. dental.2009.07.002

14. Sharafeddin F, Nouri H, Koohpeima F. The Effect of Temperature on Shear Bond Strength of Clearfil SE Bond and Adper Single Bond Adhesive Systems to Dentin. J Dent (Shiraz). 2015;16:10-6.

15. Peumans M, De Munck J, Van Landuyt K, Van Meerbeek B. Thirteenyear randomized controlled clinical trial of a two-step self-etch adhesive in non-carious cervical lesions. Dent Mater. 2015;3:308-14. https://doi. org/10.1016/j.dental.2015.01.005

16. Pashley DH, Tay FR. Aggressiveness of contemporary self-etching adhesives. Part II: etching effects on unground enamel. Dent Mater. 2001;17:430-44. https://doi.org/10.1016/S0109-5641(00)00104-4

17. Tay FR, King NM, Suh BI, Pashley DH. Effect of delayed activation of light-cured resin composites on bonding of all-in-one adhesives. J Adhes Dent. 2001;3:207-25.

18. Alex G. Universal adhesives: the next evolution in adhesive dentistry? Compend Contin Educ Dent. 2015;36:15-26.

19. Hashimoto M, Fujita S, Endo K. Bonding of self-etching adhesives on dehydrated dentin. J Adhes Dent. 2011;13:49-54.

20. Van Landuyt KL, Peumans M, De Munck J, Lambrechts P, Van Meerbeek B. Extension of a one-step self-etch adhesive into a multi-step adhesive. Dent Mater. 2006;22:533-44. https://doi.org/10.1016/j.dental.2005. 05.010

21. Carvalho RM, Garcia FC, E Silva SM, Castro FL. Critical appraisal: adhesive-composite incompatibility, part I. J Esthet Restor Dent 2005;17:129-34. https://doi.org/10.1111/j.1708-8240.2005.tb00099.x

22. Marshall GW Jr, Marshall SJ, Kinney JH, Balooch M. The dentin substrate: structure and properties related to bonding. J Dent. 1997;25:441-58. https://doi.org/10.1016/S0300-5712(96)00065-6

23. Kim YK, Min BK, Son JS, Kim KH, Kwon TY. Influence of different drying methods on microtensile bond strength of self-adhesive resin cements to dentin. Acta Odontol Scand. 2014;72:954-62. https://doi.org/10.3109 /00016357.2014.926024

24. Adebayo OA, Burrow MF, Tyas MJ. Bonding of one-step and twostep self-etching primer adhesives to dentin with different tubule orientations. Acta odontol. scand. 2008;66:159-168. https://doi. org/10.1080/00016350802123118

25. Camilotti V, Grullón PG, Mendonça MJ, D'Alpino PH, Gomes JC Influence of different light curing units on the bond strength of indirect resin composite restorations. Braz Oral Res. 2008;22:164-9. https://doi. org/10.1590/S1806-83242008000200012

26. Singh K, Naik R, Hegde S, Damda A. Shear Bond Strength of Superficial, Intermediate and Deep Dentin In Vitro with Recent Generation Self-etching Primers and Single Nano Composite Resin. J Int Oral Health. 2015; 7:28-32.

27. Sattabanasuk $V$, Shimada Y, Tagami J. The bond of resin to different dentin surface characteristics. Oper Dent. 2004;29:333-41.

28. Ikeda M, Tsubota K, Takamizawa T, Yoshida T, Miyazaki M, Platt JA. Bonding durability of single-step adhesives to previously acid-etched dentin. Oper Dent. 2008;33:702-9. https://doi.org/10.2341/08-26 